(RESEARCH ARTICLE)

\title{
Giant accessory spleen and rotating ectopic kidney: A rare association
}

De Moura Diógenis Barbosa 1, Rocha Lara Valeska de Medeiros ${ }^{1}$, Da Silva João Luís Gomes ${ }^{1}$, Júnior Eusamar Magalhães 1, Rocha Lauanda Ênia de Medeiros 1, Wanderley Neto Antonio Bizerra 1, Rêgo Amália Cinhtia Meneses ${ }^{2}$ and Araújo-Filho Irami ${ }^{3, *}$

\begin{abstract}
${ }^{1}$ Medical Students of the Federal University of the State of Rio Grande do Norte - UFRN. Multicampi School of Medical Sciences of Rio Grande do Norte - Brazil.

${ }^{2}$ Postgraduate Program in Biotechnology at Potiguar University / UnP - Laureate International Universities. Teaching and Research Manager - School of Health - League Against Cancer Natal - RN / Brazil. Ph.D. in Health Science.

3 Postgraduate Program in Biotechnology at Potiguar University/UnP - Laureate International Universities; Full Professor Department of Surgery, Federal University of Rio Grande do Norte. Full Professor, Department of Surgery, Potiguar University. Ph.D. in Health Science/ Natal-RN, Brazil.
\end{abstract}

Publication history: Received on 25 January 2020; revised on 04 February 2020; accepted on 06 February 2020

Article DOI: https://doi.org/10.30574/wjarr.2020.5.2.0021

\begin{abstract}
The accessory spleen is a congenital disability characterized by a separated ectopic splenic parenchyma. Wandering spleen (WS) is a rare condition where the spleen, free from its ligaments, is allowed to move inside the abdomen, predisposing the patient to life-threatening complications due to torsion of the vascular pedicle; splenic infarction, portal hypertension, bleeding and acute abdomen may occur. WS or Accessory Spleen (AS) is rarely suspected at presentation since symptoms are usually not specific, and definitive diagnosis is often reached only by imaging technologies such as color flow ultrasonography and angio-spiral computed tomography. The size is rarely more than $4 \mathrm{~cm}$. Patients rarely present symptoms, and the diagnosis can be accidental when faced with ectopia in radiological or intraoperative investigations. It is an essential clinical entity since abdomen-pelvic tumors must always be considered as differential diagnoses, requiring detailed evaluation. Surgical treatment is indicated for symptomatic patients or those with complications. On the other hand, the ectopic kidney with rotation abnormality also consists of a singular entity. Congenital anomalies of the upper urinary tract occur in 3\%-4\% of those born, most of which are followed up clinically. The present study discusses a case of symptomatic intrapelvic WS associated with an ectopic kidney with rotation anomaly, a rare union, and still with scarce reports in the literature. This study aimed to present the case of a patient with an isolated oversized accessory spleen and a review of the literature.
\end{abstract}

Keywords: Spleen; accessory spleen; Wandering spleen; Displaced spleen; Abdominal pain; Splenectomy.

\section{Introduction}

The spleen is localized between the 9th and 11th left ribs in the abdominal cavity between the gastric bottom and the left hemidiaphragm. With a weight of approximately $200 \mathrm{~g}$, it represents the largest lymphoid organ in the body [1-3]. It is fundamental for the hematological and immune system and is an essential reserve of approximately 10-20\% of the blood volume [4]. During its growth, the spleen can develop anomalies such as complete agenesis, multiple spleens or polysplenia, accessories spleens, and persistent lobulation. The accessory spleen (AS) is a congenital alteration resulting from the failure to move the splenic tissue to its definitive position in the left hypochondrium. This is a condition present in $10 \%$ of the population, located in regions such as splenic hilum or pancreatic tail, with an intrapelvic location being unusual [5,6]. Accessory spleen (AS) may develop during the sixth week of embryogenesis following the deposition of spleen cells along the path from the midline, usually occurring on the left side. An AS is commonly located near the

\footnotetext{
${ }^{*}$ Corresponding author

E-mail address: irami.filho@uol.com.br
} 
spleen's hilum and in the pancreas tail, and is generally asymptomatic and diagnosed incidentally during laparotomy or radiological examination performed for other reasons [7]. Adnexal masses typically originate from the genital tract; however, extrapelvic organs are rarely found in this location [8]. Although extremely rare, this possibility must be considered in the differential diagnosis of pelvic masses. Patients rarely present symptoms, and the diagnosis can be accidental when faced with ectopia in radiological or intraoperative investigations [9-11]. It is an essential clinical entity since abdomen-pelvic tumors must always be considered as differential diagnoses, requiring detailed evaluation [1214]. Surgical treatment is indicated for symptomatic patients or those with complications. On the other hand, the ectopic kidney with rotation abnormality also consists of a singular entity. Congenital anomalies of the upper urinary tract occur in $3 \%$ to $4 \%$ of those born, most of which are followed up clinically [15-17]. The present study discusses a case of symptomatic intrapelvic AS associated with an ectopic kidney with rotation anomaly, a rare union, and still with scarce reports in the literature.

\section{Material and methods}

We searched the PubMed, Cochrane Database, Scopus, Web of Science, Embase, and Google Scholar databases (gray literature) using the keywords: spleen, accessory spleen, wandering spleen; displaced spleen; abdominal pain; splenectomy. The selection of articles was made by two authors independently. A third author was consulted in case of divergence in the inclusion or not of a particular study. Reports related to accessory spleen were selected based on the chosen keywords, human studies, full-text articles, and published in English, Portuguese, or Spanish. Forty-three studies unrelated to the main objective of the review or outside the inclusion criteria were excluded after peer review. We included 26 articles from a total of 37 scientifically validated and relevant published studies. The Research Ethics Committee of Potiguar University - Natal/Brazil, approved the research after signature by the patient informed consent, according to Resolution 466/2012, of the National Commission of Ethics and Research in Humans - CONEP - Ministry of Health/Brazil. Protocol number 138/2019.

\section{Case report}

A 32-year-old male, previously healthy, sought emergency care after opening a picture of sudden low back pain of extreme intensity, radiating to the testicles, in a burning character, with no history of previous pathology or abdominal trauma. He was medicated with antispasmodics and analgesics, progressing with pain improvement. During evolution, an ultrasound examination was requested, revealing a single solid spherical nodule, with circumscribed margins, with similar, retrovesical hypoechogenic texture, with the central arterial flow at Doppler (Figure 1), suggested further investigation by computed tomography. The tomographic examination confirmed the renal ectopia on the left and the presence of a solid mass similar to the splenic parenchyma, showing a relationship with the posterior wall of the bladder and with the left seminal vesicle, an apparent cleavage plane with both, but with no evident cleavage plane with the upper rectum and a left ectopic kidney rotating $180^{\circ}$ in it longitudinal axis (Figure 2-3). After the exams, the patient developed constipation, reporting ten days without fecal eliminations, without previous episodes of illness, taking him to the gastroenterology service, where he was examined and submitted to a colonoscopy, which did not reveal any changes. He was treated with symptomatic and laxative phytotherapeutics, improving and oriented to seek general surgery service. The patient was referred and evaluated for a surgical procedure to remove the mass found in the imaging exams. With no comorbidities, no family history of neoplasms, or malformations, he underwent surgery to resolve a pilonidal cyst in childhood. We opted for exploratory laparotomy, with an encapsulated mass with a smooth violet-shiny appearance, measuring about $4.0 \times 4.0 \times 4.5 \mathrm{~cm}$ (Figure 4), with an ascending vascular pedicle invading the omentum bigger. The mass was resected and sent for anatomopathological study, which characterized tissue compatible with the accessory spleen, congested parenchyma, and atrophy of white pulp (Figure 5). After the procedure, the patient evolved without complications and was discharged in twenty-four hours, being reassessed fifteen days after the surgical intervention, favorable recovery, and no episode of pain in this period. 

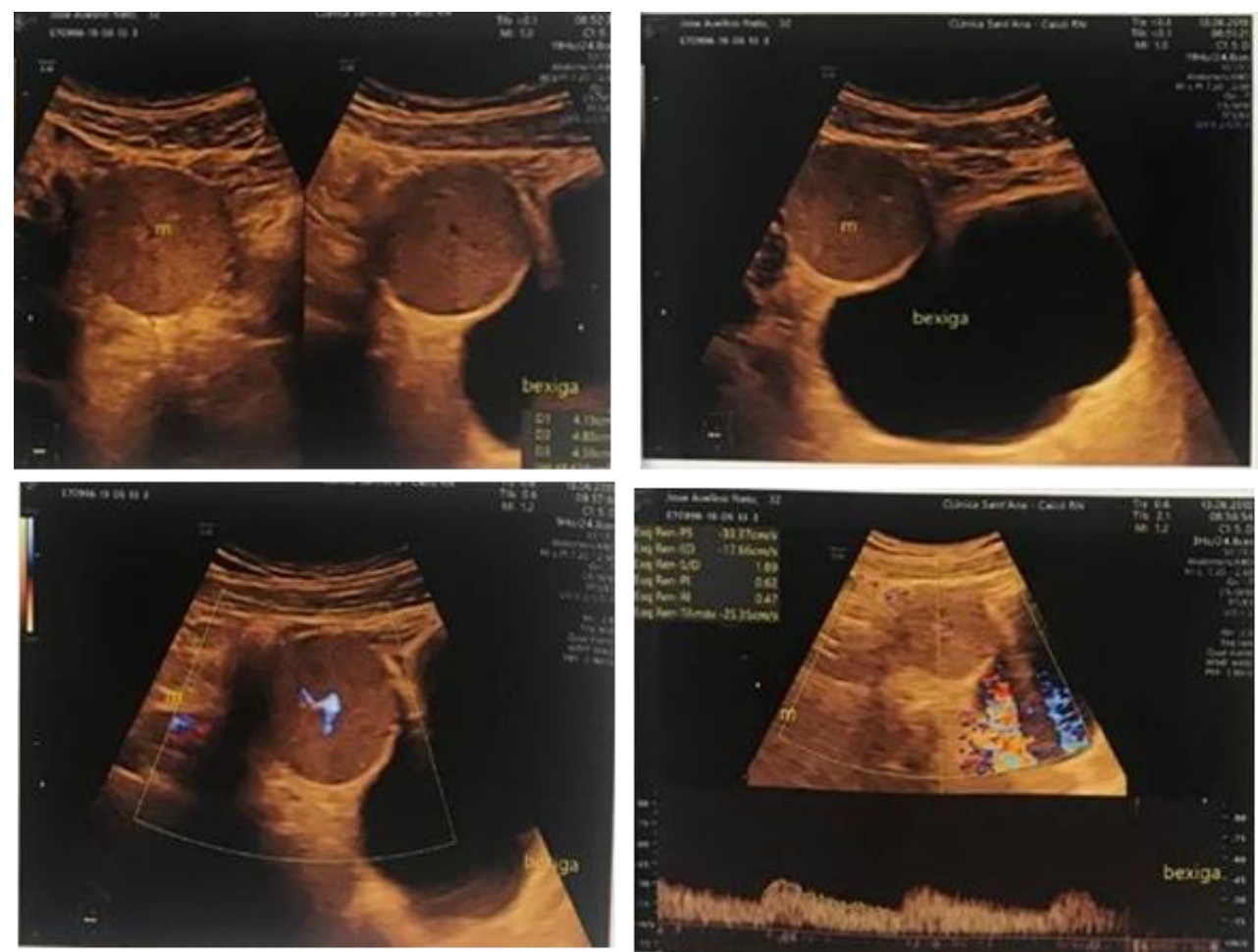

Figure 1 Pelvic ultrasound showing a single solid spherical nodule with circumscribed margins, with similar, retrovesical splenic hypoechogenic texture, with the central arterial flow at Doppler
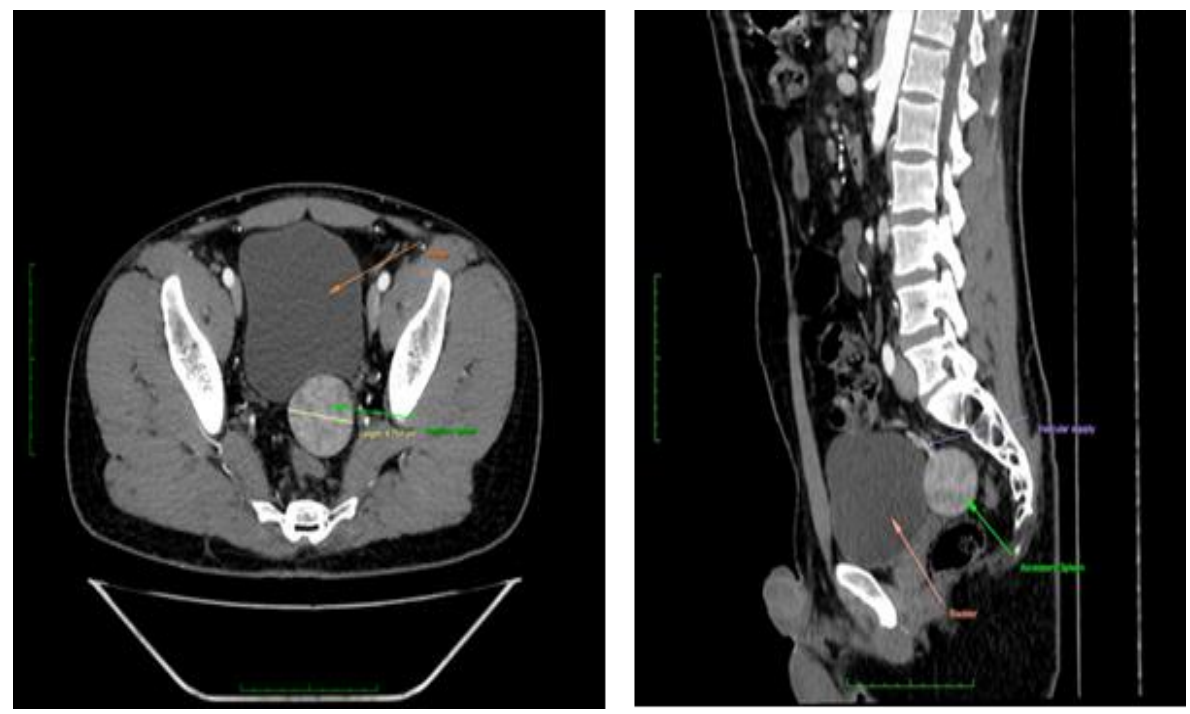

Figure 2 CT scan of the pelvis showing an ectopic spleen with a vascular pedicle. 

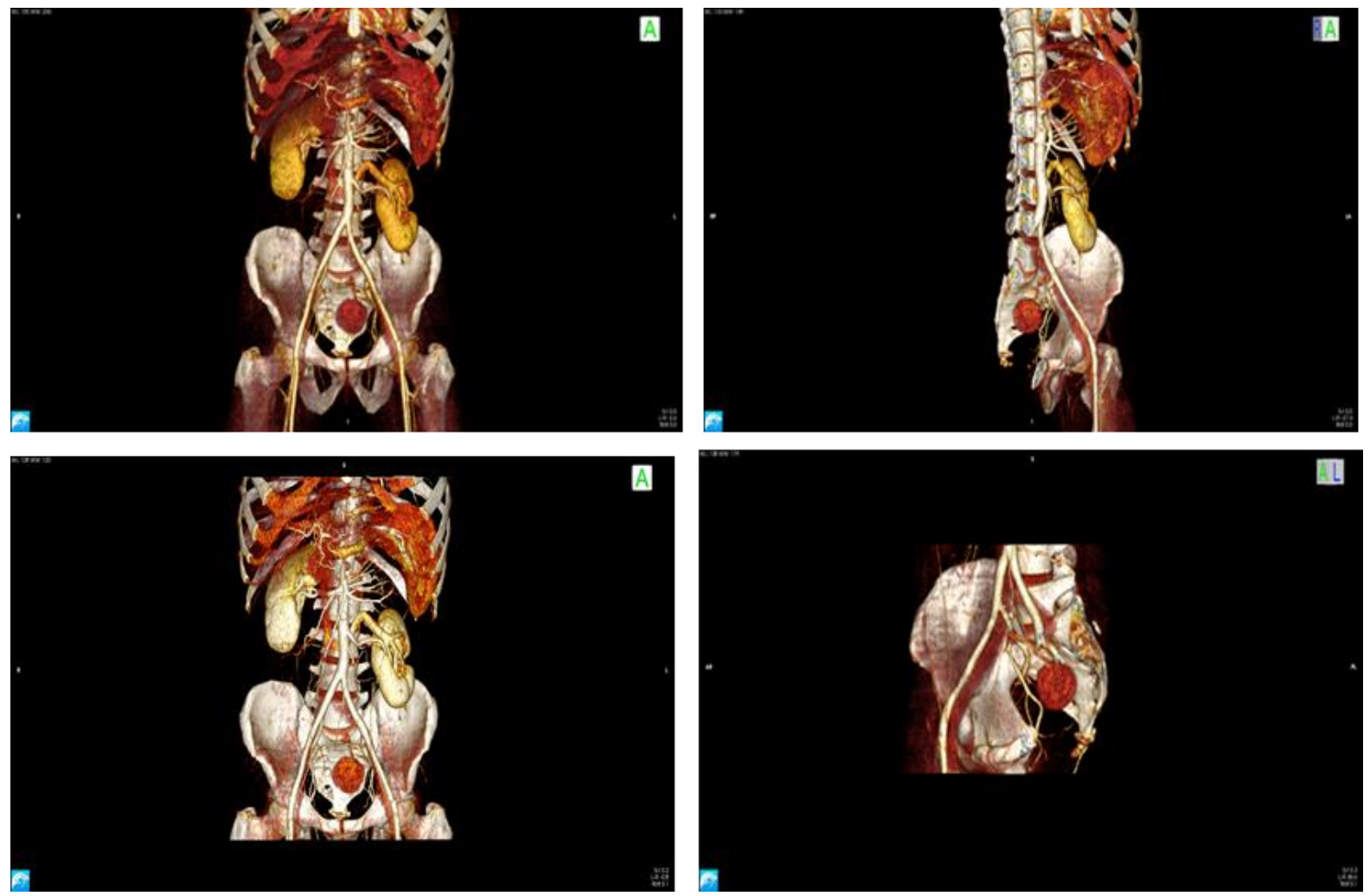

Figure 3 Pelvic 3D/CT scan - Ectopic pelvic spleen with a vascular pedicle and left kidney rotation in $180 \mathrm{o}$.
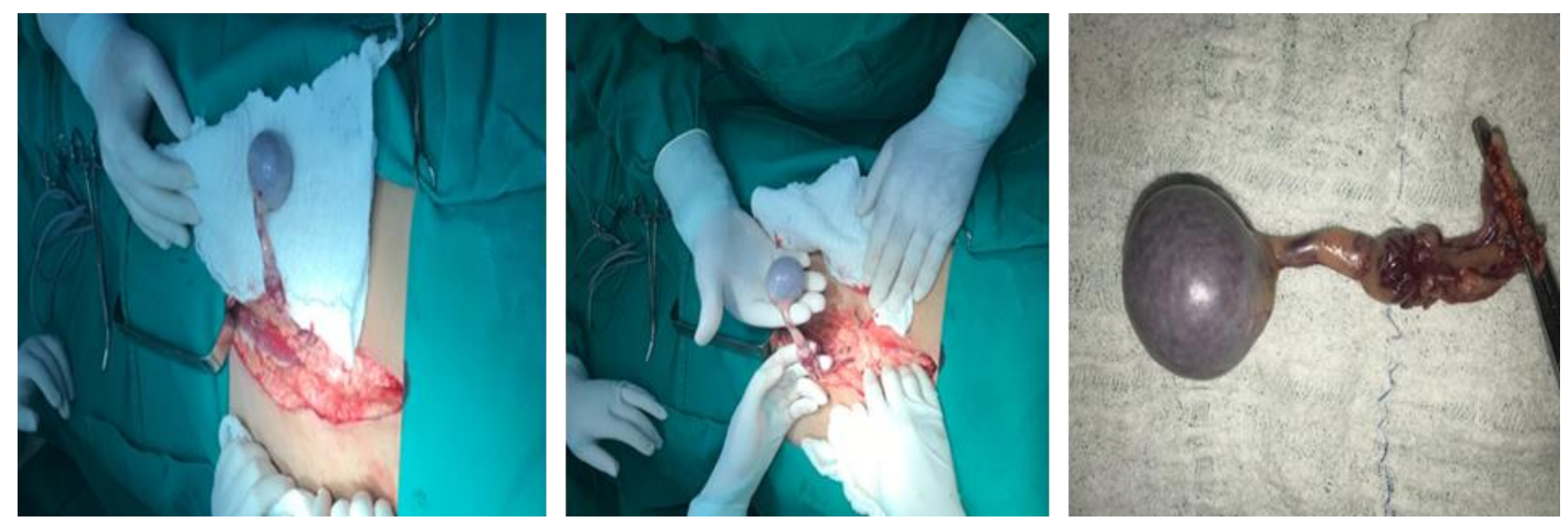

Figure 4 Exploratory laparotomy, with an encapsulated mass with a smooth violet-shiny appearance, measuring about $4.0 \times 4.0 \times 4.5 \mathrm{~cm}$, with an ascending vascular pedicle invading the omentum bigger (Ectopic spleen with a vascular pedicle). 

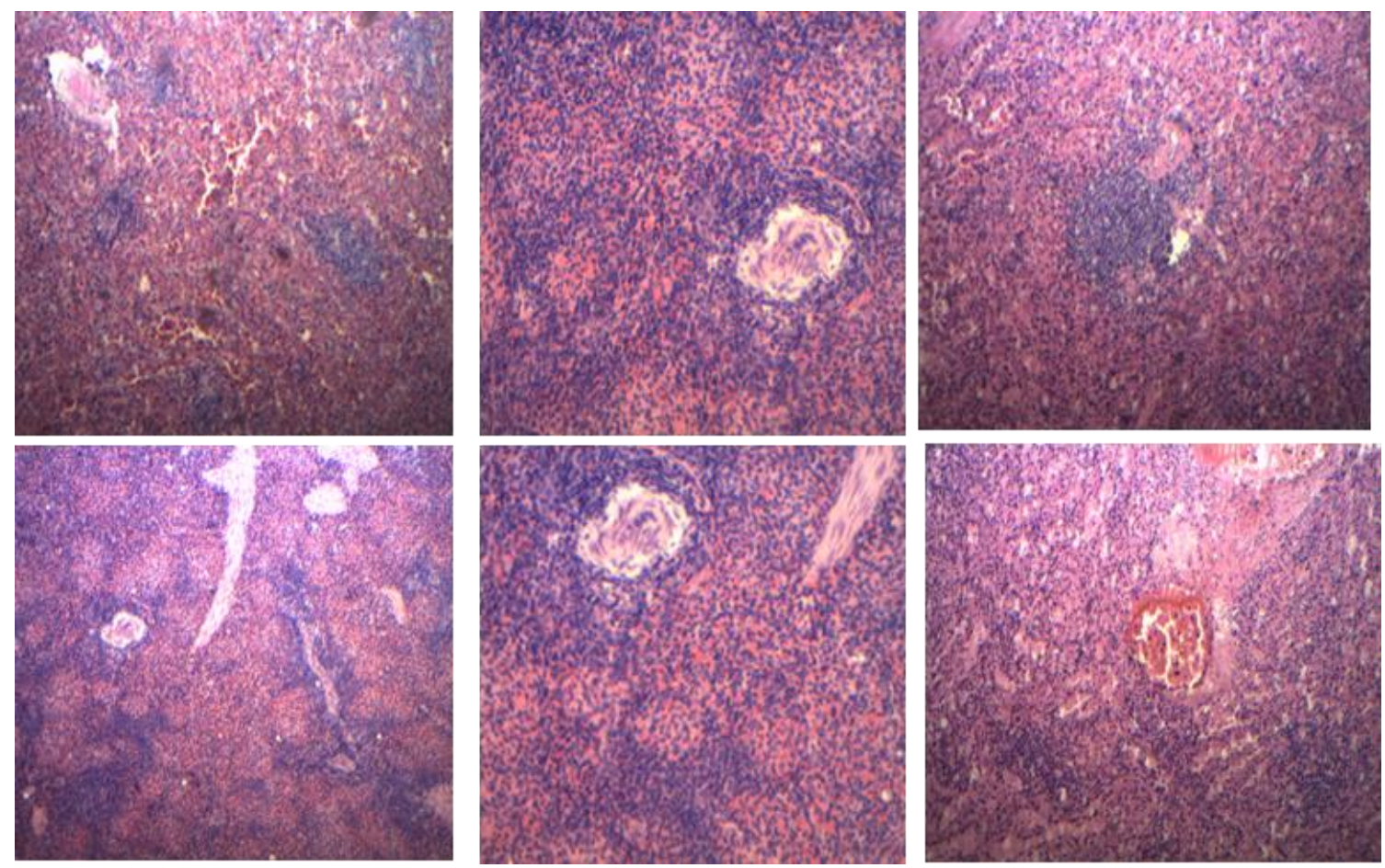

Figure 5 Anatomopathological study. Tissue compatible with the accessory spleen, congested parenchyma, and atrophy of white pulp.

\section{Discussion}

The spleen is an encapsulated organ composed of lymphatic and vascular tissue, located in the left hypochondrium [8]. Some variations in its development have already been observed, including complete agenesis, polysplenia, isolated accessory spleens, and persistent lobulations $[9,18]$. The organ begins its evolution during the fifth week of embryonic life, from the condensation of mesenchymal cells present between the layers of the dorsal mesogastrium $[7,19]$. The accessory spleen (AS) results from the formation of ectopic splenic tissue or from failure to migrate the organ, from it original site, in the midline, to it final position, in the upper left abdomen. An accessory spleen is defined as ectopic splenic tissue that develops due to the failure of cell fusion during embryonic development while migrating from the midline to the left upper quadrant $[15,16]$. They can be localized commonly next to the hilus and vascular pedicle, the tail of the pancreas, left ovary or left testis, in the greater omentum, and the mesentery of the small and the large intestine, along the greater curvature of the stomach and in the pouch of Douglas. Macroscopically, a typical accessory spleen usually appears as a solid mass, $1-2.5 \mathrm{~cm}$ in diameter. Masses larger than $4 \mathrm{~cm}$ are very rare [2,5] with a smooth, round, ovoid, or minimally lobulated shape. Microscopically, it reproduces a splenic pattern. An accessory spleen commonly has a well-defined fibrotic capsule that separates the surrounding healthy tissue [18]. According to necropsy studies, AS is present in $10 \%$ of the population [20]. Its most common locations are the splenic hilum (75\%) and the tail of the pancreas (20\%), as well as the greater omentum, greater curvature of the stomach, and mesentery [1-3]. Unver Dogan et al. investigated 720 autopsies, and BA was found in $6.7 \%$ of cases, 2 of which were pelvic. The patient in the present study presented intrapelvic AS, representing an atypical anatomical variety and with few reports in the scientific literature [1]. In addition to the congenital origin, in rare cases, its source is acquired, resulting from the autotransplantation of splenic tissue during splenectomy or after abdominal trauma, a process defined as splenosis. However, because this patient does not have a history of trauma or splenectomy, it is a congenital intrapelvic AS [21]. WS appears as an incidental finding, without clinical significance, with no preference for sex or race, asymptomatic and accidentally diagnosed during radiological investigations or abdominal surgeries [13-15]. Thus, the report of low back pain with irradiation to testicles is another peculiarity of the present case, since symptoms, as a rule, are uncommon. Due to the clinical presentation, renal lithiasis was suspected, analgesic drugs were prescribed, and an abdominal ultrasound was requested for diagnostic confirmation [18,22]. USG did not show signs of nephrolithiasis but found a solid pelvic nodule with unspecific echographic characteristics. Rectal tumor, bladder tumor, lymphadenomegaly, abscess, retroperitoneal fibrosis, and other masses of intrapelvic location form hypotheses suggested in these circumstances [14,23]. A CT scan was performed, given the demand for more accurate imaging evaluation. The report showed a nodule with behavior similar to the splenic parenchyma during the dynamic contrast phase when BA was 
then included in the list of differential diagnoses. Preoperative diagnosis of the accessory spleen is difficult, especially in emergencies [17-19,24]. CT scans show a well-margined mass, similar to the splenic parenchyma on the contrast phase. Magnetic imaging can also be used to evaluate tissue aspects and the vascular pedicle of the accessory spleen. Only nuclear medicine imaging can confirm the diagnosis with scintigraphy performed with 99mTC-labelled colloids or TC-99 m heat-damaged red blood cells because the colloid labeled with TC $99 \mathrm{~m}$ is taken from the reticulumendothelium and makes visible the spleen, liver and bone marrow; however, it is necessary to suspect the diagnosis of accessory spleen for this procedure [22]. Therefore, often only surgical excision can safely confirm the diagnosis [23, 25]. For these reasons, many surgical procedures have been done for diagnosis. Laparotomy was performed for resection of the lesion and anatomopathological study, whose report confirmed splenic tissue. The open road was chosen due to the retrovesical location and the team's more significant experience with this technique [14-16]. However, the laparoscopic approach is also an option for treatment. Torsion, spontaneous rupture, hemorrhage, and cystic formations are responsible for the clinical condition of symptomatic patients, but they are rare complications $[9,18]$. The congestion demonstrated by light microscopy was the probable cause of the symptoms in the patient in question. It is worth mentioning another anatomical variety presented by the patient, detected by imaging exams (USG and CT): ectopia and 180 rotation of the left kidney, characterizing an exaggerated kidney over-rotation [11, 17]. Congenital anomalies of the upper urinary tract involving kidneys and ureters occur in 3\% to 4\% of those born, with abnormalities in the shape and position of the organs being the most common [7,23]. Most of these renal anomalies are followed clinically, requiring a correct diagnosis of the morphological alteration, as well as the evaluation of possible complications [24-26]. During the review of the literature on the topic, the authors not found reports of an association between an accessory spleen and an ectopic kidney. Despite this, this variety did not affect the patient's symptoms in this case.

\section{Conclusion}

In conclusion, the present study demonstrated a rare case of the pelvic accessory spleen associated with a $180^{\circ}$ renal rotation that was only definitively elucidated in the intraoperative period. An accessory spleen can be variously located, and the pelvic position is hugely uncommon. Preoperative diagnosis is still tricky, especially in an emergency, and as in our case, the literature shows the difficulty of reaching a diagnosis before surgery. The main misdiagnosis is a neoplastic disease, and for this reason, accessory spleen could be wrongly removed. For this reason, undiagnosed pre or intraoperative pelvic mass, firmly to the spleen, has to be managed carefully. Despite pelvic AS being a rare, usually asymptomatic, pelvic mass condition, it should be considered in the differential diagnosis of symptomatic pelvic masses.

\section{Compliance with ethical standards}

\section{Acknowledgments}

The authors thank the Chief Surgeon and Full Professor, Department of Surgery, Federal University of Rio Grande Norte/Brazil, Prof. Dr. Aldo da Cunha Medeiros, for his contribution and relevance scientific discussion and the supervision of this research, acting as an expert consultant on the bibliographic survey, analysis, and scientific advice. We also thank all the study components for their dedication and effort to build a scientifically validated quality study.

\section{Disclosure of conflict of interest}

There are no conflicts of interest to declare by any of the authors of this study.

\section{Statement of ethical approval}

If studies involve use of animal/human subject, authors must give appropriate statement of ethical approval. If not applicable then mention 'The present research work does not contain any studies performed on animals/humans subjects by any of the authors'.

\section{Statement of informed consent}

If studies involve information about any individual e.g. case studies, survey, interview etc., author must write statement of informed consent as "Informed consent was obtained from all individual participants included in the study." 


\section{References}

[1] Unver Dogan N, Uysal II, Demirci S, Dogan KH and Kolcu G. (2011). Accessory spleens at autopsy. Clin Anat, 24(6), 757-62.

[2] Padilla D, Ramia JM, Martin J, Pardo R, Cubo T and Hernandez-Calvo J. (1999). Acute abdomen due to spontaneous torsion of an accessory spleen. Am J Emerg Med, 17(4), 429-30.

[3] Radu CC, Muțiu G and Pop 0. (2014). Accessory spleen. Rom J Morphol Embryol, 55(3 Suppl), 1243-1246.

[4] Ungör B, Malas MA, Sulak O and Albay S. (2007). Development of spleen during the fetal period. Surg Radiol Anat, 29(7), 543-550.

[5] Azar GB, Awwad JT and Mufarrij IK. (1993). Accessory spleen presenting as adnexal mass. Acta Obstet Gynecol Scand, 72(7), 587-588.

[6] Yee LF, Carvajal SH, de Lorimier AA and Mulvihill SJ. (1995). Laparoscopic splenectomy. The initial experience at University of California, San Francisco. Arch Surg, 130(8), 874-877.

[7] Obuchi T, Takagane A, Sato K, Yonezawa H, Funato O and Kobayashi M. (2017). Single-incision laparoscopic excision of symptomatic accessory spleen in the pelvis: An initial report. J Minim Access Surg, 13(4), 321-322.

[8] Ota H, Ojima Y, Sumitani D and Okajima M. (2016). Dynamic computed tomography findings of an accessory spleen in the pelvis: a case report. Surg Case Rep, 2(1), 23.

[9] Taskin MI, Baser BG, Adali E, Bulbul E and Uzgoren E. (2015). Accessory spleen in the pelvis: A case report. Int J Surg Case Rep, 12, 23-5.

[10] Cowles RA and Lazar EL. (2007). Symptomatic pelvic accessory spleen. Am J Surg, 194(2), 225-6.

[11] Ozeki M, Asakuma M, Go N, Ogura T, Inoue Y, Shimizu T, Hirokawa F, Yamamoto K, Hayashi M, Narumi Y, Higuchi $\mathrm{K}$ and Uchiyama K. (2015). Torsion of an accessory spleen: a rare case preoperatively diagnosed and cured by single-port surgery. Surg Case Rep, 1(1), 100.

[12] Chan KC and Chang YH. (2002). Acute abdomen due to torsion of a pelvic wandering spleen. J Formos Med Assoc, 101(8), 577-80. Erratum in: J Formos Med Assoc, 101(9), 674.

[13] Yousef Y, Cameron BH, Maizlin ZV and Boutross-Tadross O. Laparoscopic excision of infarcted accessory spleen. J Laparoendosc Adv Surg Tech A, 20(3), 301-303.

[14] Benevento A, Boni L, Dionigi G, Ferrari A and Dionigi R. (2002). Emergency laparoscopic splenectomy for "wandering" (pelvic) spleen: case report and review of the literature on laparoscopic approach to splenic diseases. Surg Endosc, 16(9), 31364-1365.

[15] Vural M, Kacar S, Koşar U and Altin L. (1999). Symptomatic wandering accessory spleen in the pelvis: sonographic findings. J Clin Ultrasound, 27(9), 534-536.

[16] Nobre S and Salgado C. Sudden abdominal pain is it a surprise? Necrosis of an ectopic spleen. (2011). Cir Pediatr, 24(2), 122-125.

[17] Velanovich V and Shurafa M. (2000). Laparoscopic excision of accessory spleen. Am J Surg, 180(1), 62-4.

[18] Palumbo V, Mannino M, Teodoro M, Menconi G, Schembari E, Corsale G, Di Carlo I and Toro A. (2019). An extremely rare case of an oversized accessory spleen: case report and review of the literature. BMC Surg, 27,19(1), 45.

[19] Barabino M, Luigiano C, Pellicano R, Giovenzana M, Santambrogio R, Pisani A, Ierardi AM, Palamara MA, Consolo P, Giacobbe G, Fagoonee S, Eusebi LH and Opocher E. (2019). "Wandering spleen" as a rare cause of recurrent abdominal pain: a systematic review. Minerva Chir,74(4),359-363.

[20] Hui Lian H, Hayati F, Ali AA, Azizan N, Che Ani MF, Suhaili MA and Zakaria AD. (2018). Wandering spleen: a unique cause of acute abdomen. Folia Morphol, 77(2), 400-402.

[21] Tagliabue F, Chiarelli M, Confalonieri G, Pesenti G, Beretta S, Cappello A, Fumagalli LAM and Costa M. (2018). The Wandering Spleen. J Gastrointest Surg, 22(3), 546-547.

[22] Makhlouf NA, Morsy KH, Ammar S, Mohammed RA, Yousef HA and Mostafa MG. (2016). Wandering spleen in the pelvic region in an adult man with symptoms of acute abdomen. Arab J Gastroenterol, 17(1), 49-52. 
[23] Puranik AK, Mehra R, Chauhan S and Pandey R. (2017). Wandering spleen: a surgical enigma. Gastroenterol Rep, 5(3), 241-243.

[24] Yoldaş Ö, Karabuğa T, Özsan İ, Şahin E, Limon Ö and Aydın Ü. (2015). Laparoscopic splenectomy for a wandering spleen causing chronic pelvic pain. Ulus Cerrahi Derg, 19, 32(4), 292-294.

[25] Perin A, Cola R and Favretti F. (2014). Accessory wandering spleen: Report of a case of laparoscopic approach in an asymptomatic patient. Int J Surg Case Rep, 5(12), 887-889.

[26] Magowska A. (2013). Wandering spleen: a medical enigma, it natural history and rationalization. World J Surg, $37(3), 545-550$.

\section{How to cite this article}

De Moura DB, Rocha LD, Da Silva JG, Júnior EM, Rocha LD, Wanderley Neto AB, Rêgo ACM and Araújo-Filho I. (2020). Giant accessory spleen and rotating ectopic kidney: a rare association World Journal of Advanced Research and Reviews, 5(2), 26-33. 